\title{
Avaliação geomorfométrica e uso e ocupação do solo na bacia hidrográfica do Rio Aguiar, Paraíba, Brasil: uma abordagem ambiental baseada em SIG
}

A caracterização geomorfométrica, bem como a avaliação do uso e ocupação do solo de bacias hidrográficas, são abordagens essenciais para o entendimento do comportamento hidrológico destes recortes naturais, em especial, quando associadas ao Sistema de Informações Geográficas (SIG). Neste contexto, o presente estudo, tem por objetivo, avaliar os parâmetros geomorfométricos e o uso e ocupação do solo na bacia hidrográfica do Rio Aguiar (BHRA), por meio de ambiente SIG. Para realização do estudo foi utilizado o software livre QGIS, sendo definida a delimitação da BHRA por meio de imagens Shuttle Radar Topography Mission (SRTM) e quantificados os aspectos geomorfométricos. Como resultados, foi encontrado uma área de $1096,37 \mathrm{Km}^{2}$, um perímetro de $169 \mathrm{~km}$, uma densidade de drenagem de $0,460 \mathrm{Km} \cdot \mathrm{Km}^{2}$, declividade média de $15,6 \%$, tempo de concentração de 11,36 horas, hierarquia fluvial de quarta ordem e amplitude altimétrica de $353 \mathrm{~m}$, em uma bacia com $36,8 \%$ de sua área antropizada. Através destes resultados, conclui-se que a predominância de vegetação natural e o formato alongado da BHRA indicam que a área de estudo não está sujeita a inundações e consequentemente, menores produções de sedimentos durante o escoamento superficial, como também, a abordagem em ambiente SIG identificou áreas em discordância com o Código Florestal Brasileiro vigente.

\section{Geomorphometric assessm ent and land use and occupation in the Aguiar River hydrographic basin, Paraíba, Brasil: an environmental approach based on GIS}

\begin{abstract}
The geomorphometric characterization, as well as the evaluation of the use and occupation of the watershed basins, are essential approaches for the understanding of the hydrological behavior of these natural cuts, especially when associated with the Geographic Information System (GIS). In this context, the present study aims to evaluate the geomorphometric parameters and the use and occupation of the soil in the Rio Aguiar hydrographic basin (BHRA), through the GIS environment. To conduct the study, the free software QGIS was used, defining the boundary of BHRA through Shuttle Radar Topography Mission (SRTM) images and quantifying the geomorphometric aspects. As a result, an area of $1096.37 \mathrm{Km}^{2}$ was found, a perimeter of $169 \mathrm{~km}$, a drainage density of $0.460 \mathrm{Km} . \mathrm{Km}^{-2}$, average slope of $15.6 \%$, concentration time of 11.36 hours, river hierarchy fourth-order and altimetric amplitude of $353 \mathrm{~m}$, in a basin with $36.8 \%$ of its anthropized area. Through these results, it is concluded that the predominance of natural vegetation and the elongated shape of BHRA indicate that the study area is not subject to flooding and, consequently, lower sediment production during runoff, as well as the approach in GIS environment identified areas at variance with the current Brazilian Forest Code.
\end{abstract}

Keywords: Water Resources; Semiarid; Geoprocessing.

Topic: Engenharia Ambiental

Reviewed anonymously in the process of blind peer.

Tássio Jordan Rodrigues Dantas da Silva (iD Universidade Estadual da Paraíba, Brasil http://lattes.cnpq.br/1991160864996557 http://orcid.org/0000-0002-1708-5472 tassiojordan@hotmail.com

Laércio Leal dos Santos (iD

Universidade Estadual da Paraíba, Brasil http://lattes.cnpq.br/6344196123061264 http://orcid.org/0000-0002-8175-4378

laercioeng@yahoo.com.br

\section{William de Paiva (iD}

Universidade Estadual da Paraíba, Brasil http://lattes.cnpq.br/2612977983185686 http://orcid.org/0000-0003-0220-1247 w.paiva461@gmail.com

d

DOI: 10.6008/CBPC2179-6858.2021.004.0033
José Ludemario da Silva Medeiros (iD) Universidade Estadual da Paraíba, Brasil http://lattes.cnpq.br/4084311510300833 http://orcid.org/0000-0002-7523-9601 joseludemariomedeiros@gmail.com

Maxsuel Bezerra do Nascimento (id Universidade Estadual da Paraíba, Brasil http://lattes.cnpq.br/7100621157794567 http://orcid.org/0000-0001-6381-2688

maxsuel10gba@hotmail.com

\section{Olávio Rocha Neto (iD}

Universidade Estadual da Paraíba, Brasil http://lattes.cnpq.br/9750143696204633 http://orcid.org/0000-0003-0152-5397

olavorochaneto12@gmail.com

Daniele de Almeida Carreiro
Universidade Federal de Campina Grande, Brasil
http://lattes.cnpq.br/9699288232397582
$\frac{\text { http://orcid.org/0000-0002-4192-562X }}{\text { danielealmeida23@gmail.com }}$
Jéssica Araújo Leite Martildes (D)
Universidade Estadual da Paraíba, Brasil
http://lattes.cnpq.br/4861712674645692
http://orcid.org/0000-0003-0229-6426
jessmartildes@gmail.com
Andreia Freitas Silva (D)
Universidade Estadual da Paraíba, Brasil
http://lattes.cnpq.br/2919183251860456
http://orcid.org/0000-0002-3737-5856
andreiafreitassilva@gmail.com

Referencing this:

SILVA, T. J. R. D.; SANTOS, L. L.; PAIVA, W.; MEDEIROS, J. L. S.; NASCIMENTO, M. B.; ROCHA NETO, O.; CARREIRO, D. A.; MARTILDES, J. A.; SILVA, A. F.. Avaliação geomorfométrica e uso e ocupação do solo na bacia hidrográfica do Rio Aguiar, Paraíba, Brasil: uma abordagem ambiental baseada em SIG. Revista Ibero Americana de Ciências Ambientais, v.12, n.4, p.426-438, 2021. DOI: http://doi.org/10.6008/CBPC2179-6858.2021.004.0033 
Avaliação geomorfométrica e uso e ocupação do solo na bacia hidrográfica do Rio Aguiar, Paraíba, Brasil: uma abordagem ambiental baseada

\section{INTRODUÇÃO}

O crescimento populacional é sem dúvidas um dos principais problemas do planeta, em especial, o seu impacto na disponibilidade hídrica mundial e mais precisamente nas regiões semiáridas. Atualmente, a elevada densidade demográfica e a rápida urbanização ao lado de uma maior frequência nas irregularidades pluviométricas, dificultam o planejamento e a gestão dos recursos hídricos (ZUFFO et al., 2017).

O Brasil é um país beneficiado no que diz respeito à disponibilidade hídrica, tendo cerca de $12,5 \%$ de toda reserva de água doce do planeta (ANA, 2012). Embora, a má distribuição deste recurso acarreta a carência por indisponibilidade d’água em várias regiões, entre elas, destaca-se o semiárido nordestino, assim, evidenciando uma clara necessidade de investigação dos recursos hídricos.

As bacias hidrográficas, exibem-se como recortes territoriais que proporcionam as atividades de organização e gestão ambiental em diversas áreas, privilegiando a implantação de propostas focadas para a manutenção dos recursos naturais, o contentamento das necessidades humanas e a prosperidade econômica, fundamentadas nas diretrizes da sustentabilidade (FARIAS et al., 2016; VASCONCELOS et al., 2019). No Brasil, foi a partir da década de 1980 que ocorreu uma maior intensificação de pesquisas/estudos tendo em conta a análise morfométrica em bacias hidrográficas como parâmetro de apoio para gestão, planejamento e estudos ambientais mais eficazes (ALVES et al., 2015).

Estes sistemas de drenagem são células naturais básicas para o pleno desempenho dos dispositivos ambientais, como espaços físicos para o estudo técnico-científico. Cada vez mais, estão sendo utilizadas como unidades para o gerenciamento ambiental. Sobretudo, em função do mal-uso dos recursos naturais e das elevadas taxas de antropização destes recortes (PHILIPPI JÚNIOR et al., 2019). Em vista disso, a avaliação do uso e ocupação do solo em uma bacia hidrográfica configura-se como uma ótima ferramenta para o planejamento e mapeamento da utilização racional dos recursos hídricos, e pode colaborar na geração de informações para a conjuntura da conservação ambiental, auxiliando gestores e pesquisadores (LOPES et al., 2016).

A análise quantitativa dos parâmetros morfométricos em bacias de drenagem é valiosa para sua caracterização, classificação, na quantificação e hierarquização dos canais de drenagem, sobretudo, fornecendo informações/ parâmetros essenciais ao seu desenvolvimento e para entender o seu comportamento geo-hidrológico, assim contribuindo para uma melhor abordagem dos aspectos ambientais (BANERJEE et al., 2017). Nesse contexto, dentre as ferramentas computacionais utilizadas atualmente nestes tipos de avaliações, destaca-se o Sistema de Informações Geográficas (SIG), que em conjunto com o softwere QGIS, formam um poderoso ambiente de investigação e caracterização geoespacial, com uso nas mais diversas áreas e, fornecedor de resultados de maneira rápida, precisa e econômica (ARAÚJO et al., 2020).

Diversos estudos na área de análise de parâmetros morfométricos em bacias hidrográficas, utilizamse de metodologias clássicas, como as de Christofoletti (1980), Vilella et al. (1975), Strahler (1957) e Schumm (1963) para identificação de risco de inundações e aspectos geométricos das regiões em estudo, mas, atualmente, estas metodologias estão sendo incorporadas ao ambiente SIG e apresentando resultados 
bastante eficazes, como em trabalhos nacionais de Lopes et al. (2018), Santos Júnior et al. (2019) e Araújo et al. (2020). Na literatura internacional, destacam-se os manuscritos de Aher et al. (2014), Banerjee et al. (2017), e Meshram et al. (2017) na região semiárida da Índia, e o de Rahmati et al. (2019) na província de Golestan, no Irã.

O ambiente SIG também é bastante utilizado na investigação do uso e cobertura do solo e de seus impactos ambientais, tendo como exemplo as pesquisas de Andrade et al. (2017) e, Damame et al. (2019). Neste contexto, a presente pesquisa busca a integração dos parâmetros morfométricos com o uso e ocupação do solo, para melhor investigar o comportamento geo-hidrológico da área de estudo e a possível identificação de problemas ambientais, em especial, o risco de cheias, áreas de incompatibilidade legal e o nível de antropização da bacia hidrográfica, a partir do emprego de geotecnologias em ambiente SIG.

A região do presente estudo corresponde a bacia hidrográfica do Rio Aguiar, que é responsável pela recarga hídrica do Açude Mãe d’água que juntamente com o Açude Coremas formam o maior manancial superficial de água doce do estado da Paraíba - Brasil, o Sistema Hídrico Curemas-Mãe d’água (ou Açude Estevam Marinho), que, mesmo em períodos de estiagem, abastece mais de 110 municípios do semiárido brasileiro. Desta maneira, é de extrema importância a realização de estudos voltados para esta região, em especial, no âmbito desta bacia hidrográfica, visando tamanha relevância para o abastecimento público dos municípios do sertão paraibano e o fornecimento de subsídios para o melhor gerenciamento dos recursos hídricos e conservação ambiental local.

À face do exposto, teve-se por objetivo no presente trabalho, avaliar os aspectos geomorfométricos e o uso e ocupação do solo na bacia hidrográfica do Rio Aguiar, por meio de uma abordagem integrada baseada em SIG.

\section{MATERIAIS E MÉTODOS}

\section{Área de estudo}

A Bacia Hidrográfica do Rio Aguiar (BHRA), localiza-se no sudoeste do estado da Paraíba - Brasil, entre as coordenadas geográficas $07^{\circ} 10^{\prime} 26^{\prime \prime}$ e $07^{\circ} 15^{\prime} 09^{\prime \prime}$ de latitude Sul e $37^{\circ} 59^{\prime} 07^{\prime \prime}$ e $39^{\circ} 17^{\prime} 25^{\prime \prime}$ de longitude Oeste (Figura 1), na qual sua rede de drenagem atinge os municípios de Aguiar, Igaracy, Itaporanga, Bonito de Santa Fé, São José de Piranhas, Carrapateira, Serra Grande e Coremas. Ao lado da bacia hidrográfica do Rio Piancó, recarregam a maior reserva hídrica superficial do estado, o Açude Estevam Marinho, com capacidade máxima de acumulação de 1,2 bilhões de metros cúbicos.

De acordo com Koppen (1936), o clima é classificado como semiárido quente e seco do tipo BSh. As precipitações são irregulares e concentram-se de janeiro a maio (período denominado de inverno), a estiagem abrange a maior parte do ano, tendo setembro o mês mais seco, a insolação é elevada com médias entre 7,5 a 8,5 horas por dia (SOUSA et al., 2010). A vegetação é de médio e pequeno porte, caracterizada por espécies da flora que perdem as folhas durante a estiagem (caducifólias), com vasta presença de arbustos e cactáceas, típicas do bioma Caatinga (FERNANDES et al., 2018). Os solos são, em geral, rasos, cascalhentos 
e com predomínio de silte e areia, entre eles destacam-se as classes de Neossolo Litólico, Luvissolo Crômico e Argissolo Vermelho, por fim, a geologia é caracterizada, principalmente, pela estratigrafia do embasamento cristalino, com destaque para a Formação Seridó, Complexo Caicó e Complexo Piancó (SOUSA et al., 2010; SANTOS, 2017).

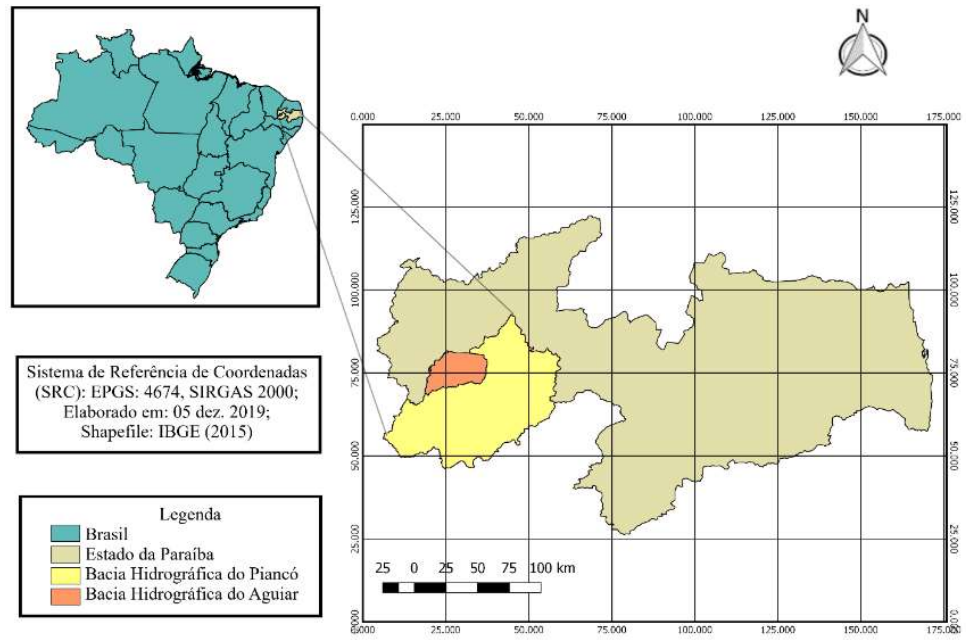

Figura 1: Localização da bacia hidrográfica do Rio Aguiar.

\section{Modelagem por meio do SIG}

A elaboração deste trabalho constou de uma abordagem integrada realizada através do uso do SIG, no software livre QGIS 3.4.5. Inicialmente, processou-se o Modelo Digital de Elevação (MDE), onde foi delimitada a área da BHRA, a partir de imagens SRTM do estado da Paraíba - Brasil, com resolução de $30 \mathrm{~m}$, coletadas na literatura digital da Agência Executiva de Gestão de Águas do Estado da Paraíba (AESA), e do Instituto Brasileiro de Geografia e Estatística (IBGE). A partir dessas fontes também foi possível extrair dados referentes à declividade, rede de drenagem e a hipsometria da BHRA e, consequentemente, auxiliou na customização dos respectivos mapas temáticos. Utilizou-se como padrão de coordenadas geográficas o sistema SIRGAS 2000 UTM 24 Sul, por meio da reprojeção dos dados vetoriais e matriciais.

Em seguida, empregou-se a metodologia de Christofoletti (1980) para obtenção dos parâmetros morfométricos: área, perímetro, comprimento axial, comprimento do rio principal, comprimento e largura média da bacia hidrográfica, razão de relevo e razão de relevo relativo. De acordo com Vilella et al. (1975), calculou-se os parâmetros: fator de forma, índice de conformação, coeficiente de compacidade, densidade de drenagem, densidade dos cursos d’água, amplitude altimétrica e as declividades de álveo. $\mathrm{O}$ tempo de concentração, o padrão de drenagem e a ordem dos cursos d’água (hierarquia fluvial) foram obtidos conforme Strahler (1957), o índice de sinuosidade do rio principal foi segundo Schumm (1963). Por fim, a definição das classes de declividade de acordo com a metodologia da EMBRAPA (2013).

A base cartográfica empregada na customização do mapa de uso e ocupação do solo da BHRA, obteve-se por meio do endereço eletrônico do United States Geological Survey (USGS), imagens do satélite Landsat $8 \mathrm{ETM}^{+}$, datadas de 05 de novembro de 2019. A partir da ferramenta semi-automatic classification plugin, no software livre QGIS 3.4.5, classificou-se a área de estudo em cinco classes de uso e ocupação do 
solo: corpos hídricos superficiais, vegetação, pastagens, urbanização e solo exposto.

\section{RESULTADOS E DISCUSSÃO}

A BHRA possui uma área de drenagem de $1096,37 \mathrm{Km}^{2}$, com um perímetro de $169,02 \mathrm{Km}$, conforme os resultados geomorfométricos apresentados na Tabela 1.

Tabela 1: Parâmetros geomorfométricos da bacia hidrográfica do Rio Aguiar.

\begin{tabular}{|c|c|}
\hline Parâmetro & Resultado \\
\hline Área $\left(\mathrm{Km}^{2}\right)$ & $1.096,370$ \\
\hline Perímetro $(\mathrm{Km})$ & 169,020 \\
\hline Comprimento axial (Km) & 54,493 \\
\hline Comprimento da bacia hidrográfica (Km) & 54,050 \\
\hline Comprimento do rio principal $(\mathrm{Km})$ & 62,200 \\
\hline Largura média da bacia hidrográfica (Km) & 19,328 \\
\hline Coeficiente de compacidade (adimensional) & 1,429 \\
\hline Fator de forma (adimensional) & 0,355 \\
\hline Índice de conformação (adimensional) & 0,369 \\
\hline Densidade de drenagem $\left(\mathrm{Km} . \mathrm{Km}^{-2}\right)$ & 0,460 \\
\hline Densidade dos cursos d’água (canais. $\mathrm{Km}^{-2}$ ) & 0,033 \\
\hline Somatório dos cursos d’água (Km) & 504,570 \\
\hline Tempo de concentração (horas) & 11,36 \\
\hline Hierarquia fluvial (ordem) & $4 \underline{a}$ \\
\hline Padrão de drenagem & Dendrítico \\
\hline Índice de Sinuosidade (adimensional) & 1,14 \\
\hline Altitude máxima $(\mathrm{m})$ & 613 \\
\hline Altitude mínima (m) & 260 \\
\hline Amplitude altimétrica $(\mathrm{m})$ & 353 \\
\hline Razão de relevo $\left(\mathrm{m} \cdot \mathrm{m}^{-1}\right)$ & 0,0065 \\
\hline Razão de relevo relativo $\left(\mathrm{m} . \mathrm{m}^{-1}\right)$ & 0,0020 \\
\hline Declividade Média (\%) & 15,6 \\
\hline Declividade de álveo S1 (m. $\left.\mathrm{m}^{-1}\right)$ & 0,005604 \\
\hline Declividade de álveo S2 (m. $\left.\mathrm{m}^{-1}\right)$ & 0,002139 \\
\hline Declividade de álveo S3 $\left(\mathrm{m} . \mathrm{m}^{-1}\right)$ & 0,001118 \\
\hline
\end{tabular}

Os baixos valores do índice de conformação (Ic), 0,369, e do fator de forma (Kf), 0,355, indicam que a BHRA não estar sujeita à enchente, afirmação comprovada pelo moderado valor do coeficiente de compacidade $(\mathrm{Kc}), 1,429$, como também, pela forma alongada da bacia hidrográfica que lembra uma folha de árvore. De acordo com Vilella et al. (1975), quanto mais próximo a um for o valor de Kc, maior será a susceptibilidade à grandes cheias, na bacia em análise, enquanto, valores gradativamente inferiores a um de Ic e Kf, apresentam menor capacidade de proporcionar inundações e, consequentemente, formato alongado (retangular) para a bacia hidrográfica.

Com base nestes fatores, Gerber et al. (2018), também identificaram baixa tendência à enchente e elevado tempo de concentração, inferido pelo formato alongado da bacia hidrográfica do rio Itajaí, no estado de Santa Catarina, Brasil. Bem como, na pesquisa realizada por Santos Júnior et al. (2019), na sub-bacia hidrográfica do rio Mutum-Paraná, na Amazônia Ocidental do Brasil, comprovaram baixa susceptibilidade às grandes cheias e baixa velocidade de escoamento superficial em condições normais de precipitação, considerando os valores de Kc $(1,491)$, Ic $(0,443)$, e Kf $(0,302)$, o que também sugere uma menor capacidade de produção de sedimentos aliada a uma boa cobertura de vegetação natural. Nascimento-Lopes et al. (2018), também evidenciaram a forma alongada e o baixo risco à enchente na bacia do rio Una-Ibiúna, 
sudoeste do estado de São Paulo, Brasil, conforme os resultados adquiridos de Kc $(2,17)$, Ic $(0,33)$, e Kf $(0,24)$.

Outro parâmetro relevante do comportamento do escoamento superficial de uma bacia hidrográfica é o tempo de concentração $(T c)$, ou seja, "o tempo em que uma gota de chuva que atinge a região mais remota da bacia hidrográfica leva para atingir o seu exutório" (TUCCI, 2004). Assim, com um Tc de 11,36 horas, a bacia do Aguiar apresenta um elevado tempo de concentração, isto devido, principalmente, a baixa densidade dos cursos d’água, apenas 0,033 canais. $\mathrm{Km}^{-2}$, e consequentemente ao fraco sistema de escoamento da bacia hidrográfica, indicado pelo baixo valor da densidade de drenagem (Dd), 0,460 Km. $\mathrm{Km}^{-}$ ${ }^{2}$, que conforme Vilella et al. (1975), enquadra-se como uma bacia de drenagem pobre.

De acordo com Meshram et al. (2017), a Dd indica as adjacências do espaçamento entre canais e é uma medida do comprimento total dos segmentos do fluxo d água de todos os trechos por unidade de área, sendo afetada por fatores como resistência ao intemperismo, permeabilidade da formação rochosa, clima e vegetação. Assim, o fraco sistema de drenagem apresentado pela BHRA pode estar relacionado ao clima semiárido, o que não contribui para o aumento do defluxo e, consequentemente, aparição de novos cursos d’água, como também, pelo fator geológico, que segundo Santos et al. (2002), apresenta estratigrafia cristalina, do embasamento, o que favorece à resistência ao intemperismo.

Em estudo realizado na bacia hidrográfica do Rio Bom Sucesso, na região semiárida do estado da Bahia - Brasil, Lima et al. (2014), também relacionaram os baixos valores de densidade dos cursos d’água $\left(0,57\right.$ canais. $\left.\mathrm{Km}^{-2}\right)$, a densidade de drenagem $\left(0,92 \mathrm{Km} \cdot \mathrm{Km}^{-2}\right)$, os baixos índices pluviométricos e a litologia local com o fraco fluxo fluvial e, consequentemente, dificuldade na formação de novos canais. A partir desta relação, estes mesmos autores também concluíram que a área de estudo tem rara capacidade de surgimento de novos canais de drenagem.

Vale destacar que, os baixos valores encontrados da densidade dos cursos d água e da densidade de drenagem, sugerem que o grau de dissecação do relevo, em geral, da BHRA é baixo. Logo, do ponto de vista da erosão do solo, o escoamento superficial se concentra em poucos canais, com isso, provocando uma maior susceptibilidade aos processos erosivos nesses locais, por outro lado, com a baixa concentração de canais, as áreas restantes, que caracterizam a maior parte, são menos afetadas por este fator.

A bacia hidrográfica do Rio Aguiar apresenta hierarquia fluvial de quarta ordem (Figura 2), o curso d`água do rio principal foi calculado em 62,2 Km de comprimento, tendo como foz o Açude Mãe d’água, no município de Coremas, Paraíba - Brasil. Obteve-se um somatório total dos cursos d’água de 504,57 Km de comprimento, com padrão de drenagem classificado conforme Strahler (1957) em dendrítico.

Os cursos d’água de primeira ordem são os que apresentam maior quantidade (74\% dos canais), como também são os que exibem as maiores extensões $(338,55 \mathrm{Km})$. A disposição espacial destes canais, apresenta-se bem distribuída entre as partes alta, média e baixa da BHRA, entretanto, observa-se uma maior concentração destes canais nos limites da bacia hidrográfica, onde estão localizadas a maior parte das nascentes do Rio Aguiar. 


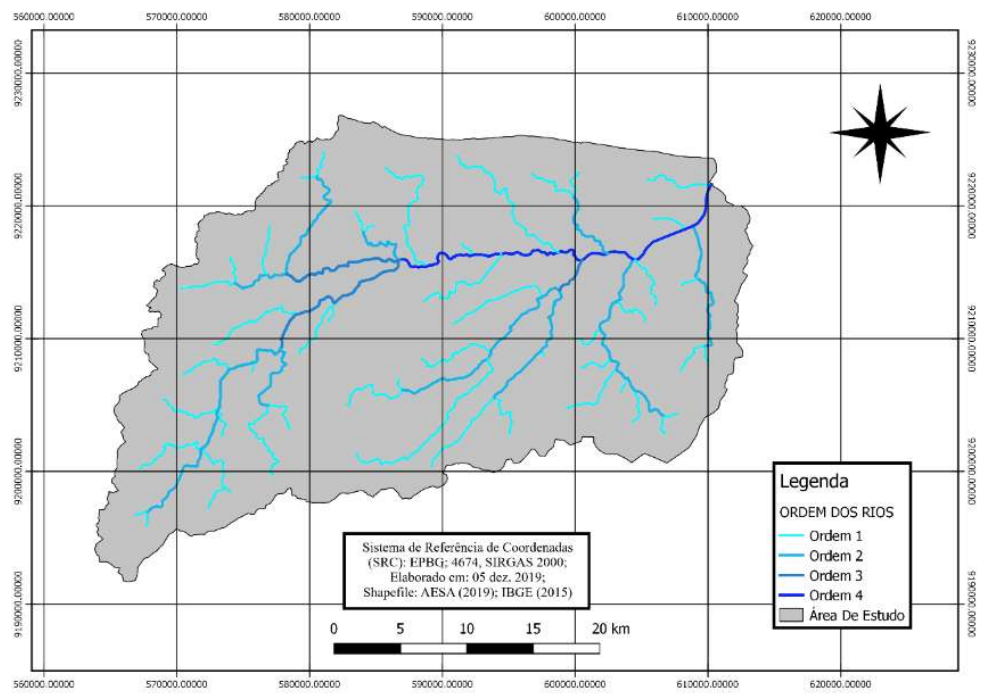

Figura 2: Rede de drenagem e hierarquia fluvial da bacia hidrográfica do Rio Aguiar.

Segundo Leal et al. (2017b), a conservação das nascentes de rios e córregos estabelece um fator primordial para manutenção de todo o equilíbrio ecossistêmico de uma bacia hidrográfica, sendo necessário também a preservação de toda área no entorno da nascente, em no mínimo um raio de $50 \mathrm{~m}$ a partir do olho d’água, conforme estabelece a Lei n.12651/2012 que traz diretrizes sobre o Código Florestal Brasileiro (BRASIL, 2012). Ressalva-se também, que a presença de impactos ambientais negativos nestas áreas, implicam, não apenas, no desequilíbrio local, mas em todo o comportamento da bacia hidrográfica, portanto, sendo indispensável a realização de estudos ambientais mais específicos nessas localidades, como a avaliação de impacto ambiental (MACHADO et al., 2018).

O Índice de Sinuosidade (Is) da BHRA, que relaciona o comprimento do rio principal com a distância em linha reta deste mesmo corpo hídrico da foz até a nascente (SCHUMM, 1963), foi calculado com Is =1,14, sinalizando que o Rio Aguiar é bastante retilíneo, com faixas verticais e poucas curvaturas, caracterizandose como um rio pouco sinuoso, ou seja, bastante reto. Essa circunstância de linearidade, sugere que a bacia hidrográfica apresente significativa declividade, agravando, assim, o quadro de arraste dos sedimentos e consequentemente, provocando um maior assoreamento dos corpos hídricos, em especial, do manancial Mãe d’água, que funciona como corpo receptor de carga hídrica superficial da bacia hidrográfica, uma vez que este manancial está localizado no exutório da BHRA.

Em estudo realizado na bacia hidrográfica do Riacho do Saco, na região semiárida do estado do Pernambuco - Brasil, Souza, Barros e Correa (2016), também identificaram um baixo índice de sinuosidade para os canais fluviais, assim, também indicando áreas propensas a acumulação de sedimentos. Para a microbacia do Córrego Ipaneminha de Baixo, no município de Sorocaba, São Paulo - Brasil, Leal et al. (2017a) também calcularam um baixo valor de Is $(1,07)$, inferido pela condição retilínea do curso d’água principal e elevada declividade da área de estudo.

De acordo com Castro et al. (2001), a altitude pode influenciar diretamente o regime pluviométrico, o clima, a temperatura e a fração de radiação que uma bacia hidrográfica recebe, mas segundo Benatti et al. (2015), um pequeno intervalo de altitude (baixa amplitude altimétrica) pouco influi na variação da 
quantidade de radiação e, por consequência, no clima, temperatura e evapotranspiração local. Nesse cenário, observa-se na Figura 3, o mapa hipsométrico da bacia hidrográfica do Rio Aguiar.

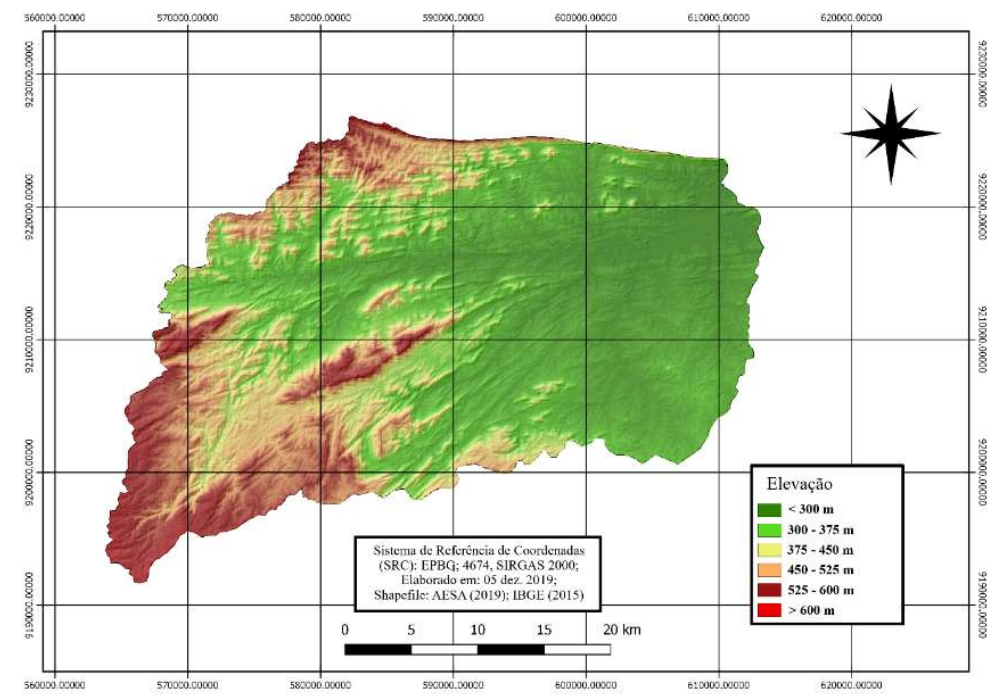

Figura 3: Hipsometria da bacia hidrográfica do Rio Aguiar.

A região sudoeste da BHRA apresentou as maiores elevações, variando de $450 \mathrm{~m}$ até $613 \mathrm{~m}$ de altitude, enquanto a porção leste da bacia, principalmente, ao aproximar-se do exutório, atingiu as menores elevações (entre 260 e 300 m). A amplitude altimétrica encontrada para a área de estudo foi de 353 m, tendo uma altitude máxima de $613 \mathrm{~m}$ e mínima de $260 \mathrm{~m}$.

Os valores de Razão de relevo ( $R r)$ e Razão de relevo relativo (Rrl) encontrados foram, respectivamente, $\mathrm{Rr}=0,0065 \mathrm{~m} \cdot \mathrm{m}^{-1} \mathrm{e} \mathrm{Rrl}=0,0020 \mathrm{~m} \cdot \mathrm{m}^{-1}$, os quais sugerem que a BHRA compreende um relevo plano a suave ondulado. Outro fator que colabora para essas características é a disposição das altitudes ao longo da bacia hidrográfica, uma vez que, apenas $22,6 \%$ da BHRA apresenta uma elevação superior à altitude média $(528,5 \mathrm{~m})$, implicando a dizer que a maior parte do território da bacia $(77,4 \%)$ está localizado em regiões abaixo da altitude média, e provavelmente, mais estáveis (suaves).

A declividade influi diretamente no nexo entre a precipitação e a infiltração do solo e, de modo consequente, na umidade do solo e no escoamento superficial, dessa maneira, quanto maior for o declive do terreno, maior será a velocidade do deflúvio, provocando a desagregação e o transporte do material erodido, como também, menor será a taxa de infiltração do solo (LEPSCH, 2016).

À face do exposto, a BHRA exibe uma declividade média de 15,6\%, logo, o relevo da bacia foi classificado como ondulado, conforme classificação da EMBRAPA (2013), sendo que, 72,5\% da área de estudo apresenta declividade inferior à média, ou seja, um relevo plano a ondulado, que se caracteriza pouco susceptível os processos erosivos (presença de baixa declividade do terreno), conforme, também pode-se observar na Figura 4 e Tabela 2. 


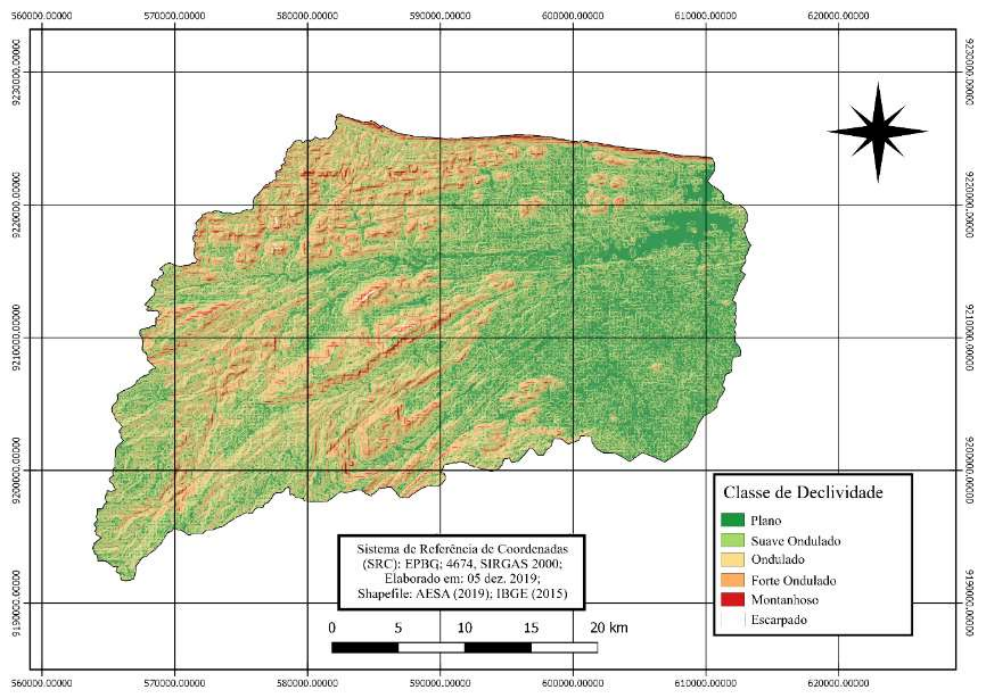

Figura 4: Mapa de declividade da bacia hidrográfica do Rio Aguiar.

Tabela 2: Distribuição das classes de declividade da bacia hidrográfica do Rio Aguiar.

\begin{tabular}{llll}
\hline Classe de & Classe de Relevo & Área & \\
\cline { 3 - 4 } Declividade (\%) & & $\mathbf{K m}^{\mathbf{2}}$ & $\mathbf{\%}$ \\
\hline $0-3$ & Plano & 82,23 & 41 \\
$3-8$ & Suave ondulado & 449,51 & 28 \\
$8-20$ & Ondulado & 306,98 & 19,5 \\
$20-45$ & Forte ondulado & 213,79 & 3,8 \\
$45-75$ & Montanhoso & 41,66 & 0,2 \\
$>75$ & Escarpado & 2,19 & $\mathbf{1 0 0}$ \\
\hline Total & - & $\mathbf{1 0 9 6 , 3 7}$ & \\
\hline
\end{tabular}

A classe de relevo com maior abrangência na BHRA foi a de relevo suave ondulado com $41 \%$ da área de estudo $\left(449,51 \mathrm{Km}^{2}\right)$, seguida por a classe ondulada com $28 \%\left(306,98 \mathrm{Km}^{2}\right)$, e posteriormente, com $19,5 \%$ da área, a classe forte ondulada $\left(213,79 \mathrm{Km}^{2}\right)$. Essa conjuntura, juntamente com o valor supracitado da declividade média, reiteram a predominância do relevo ondulado na bacia do Aguiar, em especial, nas regiões do alto e médio curso d’água (Figura 4).

Destaca-se que os baixos valores de declividade, referentes as classes de relevo plano $\left(82,23 \mathrm{Km}^{2}\right) \mathrm{e}$ suave ondulado $\left(449,51 \mathrm{Km}^{2}\right)$, as quais juntas abrangem $48,5 \%$ da área da BHRA, representam os locais com maior resistência à ação dos processos erosivos, e por conseguinte, melhor estabilidade dos solos, no que se refere ao fator declividade. Entretanto, vale ressaltar a importância da manutenção da cobertura vegetal nesses locais, assim como, em toda bacia hidrográfica, uma vez que, a cobertura vegetal assume o papel de proteção natural contra o impacto das gotas de chuva, que desgastam e transportam o solo erodido, ajuda na manutenção da umidade do solo, além de fornecer matéria orgânica e aumentar a infiltração d água no solo (BERTONI et al., 2014).

Apenas $4 \%$ da área de estudo apresentou declividade superior a $45 \%$ de declive, sendo que, 3,5\% pertencem a classe de relevo montanhoso $\left(41,66 \mathrm{Km}^{2}\right)$ e 0,2\% a classe de relevo escarpado $\left(2,19 \mathrm{Km}^{2}\right)$, na BHRA essas localidades estão concentradas nas regiões das cabeceiras do Rio Aguiar (Figura 4). Estes locais favorecem ao aumento da velocidade do escoamento superficial e, consequentemente, são as regiões mais vulneráveis à degradação dos solos, portanto, segundo o novo Código Florestal Brasileiro (Lei n.12.651 de 
2012), estas devem ser designadas como áreas de preservação (BRASIL, 2012).

A declividade de álveo, que representa as variações de instabilidade de um curso d’água, é um respeitável parâmetro na investigação da velocidade do escoamento superficial e da infiltração do solo (VILELLA et al., 1975). Para o Rio Aguiar, o valor de S1 $\left(0,005604 \mathrm{~m} \cdot \mathrm{m}^{-1}\right)$, se distanciou dos valores de S2 $\left(0,002139 \mathrm{~m} \cdot \mathrm{m}^{-1}\right)$ e S3 $\left(0,001118 \mathrm{~m} \cdot \mathrm{m}^{-1}\right)$, devido a brusca variação apresentada pelo perfil longitudinal do Rio Aguiar (Figura 5), uma vez que, o resultado de S1 leva apenas em consideração a razão entre a diferença de cotas e o comprimento do rio principal. Dentre os índices de declividade de álveo, a curva de S3 é a que melhor representa o perfil longitudinal, visto que considera durante sua aquisição o declive de todos os trechos do curso d’água em análise, além disso, vale ressaltar a considerável semelhança entre as curvas (valor) de S2 e S3, portanto, tornando-as as que melhor representam a realidade do álveo do Aguiar.

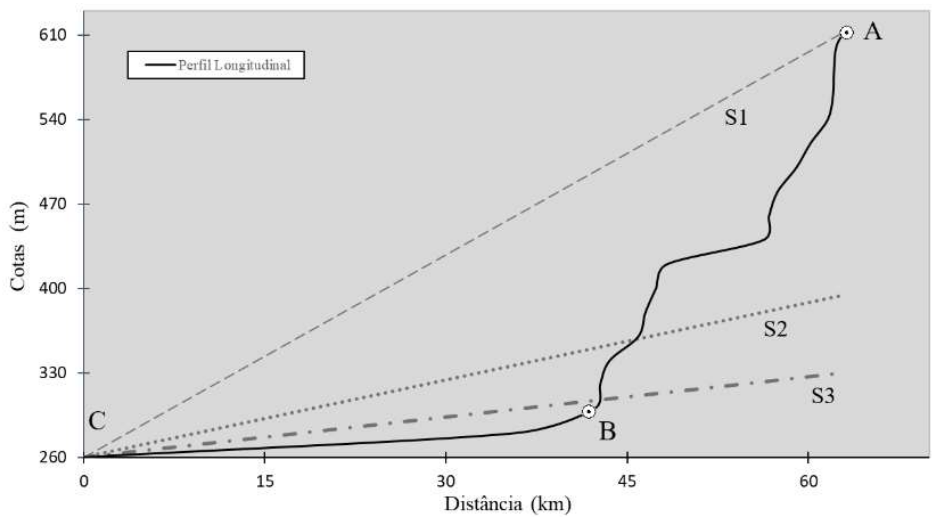

Figura 5: Perfil longitudinal do Rio Aguiar e declividades de álveo (S1, S2, S3).

O perfil longitudinal do Rio Aguiar demostra um gradiente acentuado na origem, mas gradualmente se achata à medida que o rio se deteriora em direção a sua foz. A partir dessa conjuntura, observa-se na Figura 5, que é possível distinguir o perfil longitudinal em dois seguimentos distintos. A primeira parte (seguimento $A B$ ), que tem origem na nascente do rio e prolonga-se por $21 \mathrm{Km}$ de distância, sendo caracterizado por uma declividade muito íngreme, e a segunda parte (seguimento BC), que apresenta um declive suave e seguindo por mais $41,2 \mathrm{Km}$ até chegar ao exutório da bacia hidrográfica.

À vista do exposto, pode-se afirmar que a parte inicial do perfil longitudinal (seguimento $A B$ ), apresenta alta possibilidade a susceptibilidade do solo à erosão hídrica, devido a maior força de arraste do escoamento superficial, provocada pelos elevados valores de declividade, portanto, sendo necessário a preservação da vegetação, sobretudo da mata ciliar, para estes locais. Entretanto, a baixa declividade exibida no seguimento $\mathrm{BC}$, e confirmada por os valos de S2 e S3, apontam condições favoráveis a decantação do material erodido (áreas de sedimentação), vindo há causar problemas e/ou impactos ambientais significativos, como o assoreamento das redes de drenagem.

Ao analisar a distribuição das classes de uso e ocupação do solo da BHRA (Figura 6 e Tabela 3), observa-se uma predominância da classe vegetação, com $679,75 \mathrm{Km}^{2}$, o equivalente a $62 \%$ da área de estudo. Essa característica, no geral, aponta uma tendência de estabilidade nos processos ecossistêmicos, em especial, nos recursos hídricos, posto que a presença da cobertura vegetal proporciona melhorias na 
qualidade das águas e no regime do ciclo hidrológico em bacias hidrográficas (ANDRADE et al., 2017).

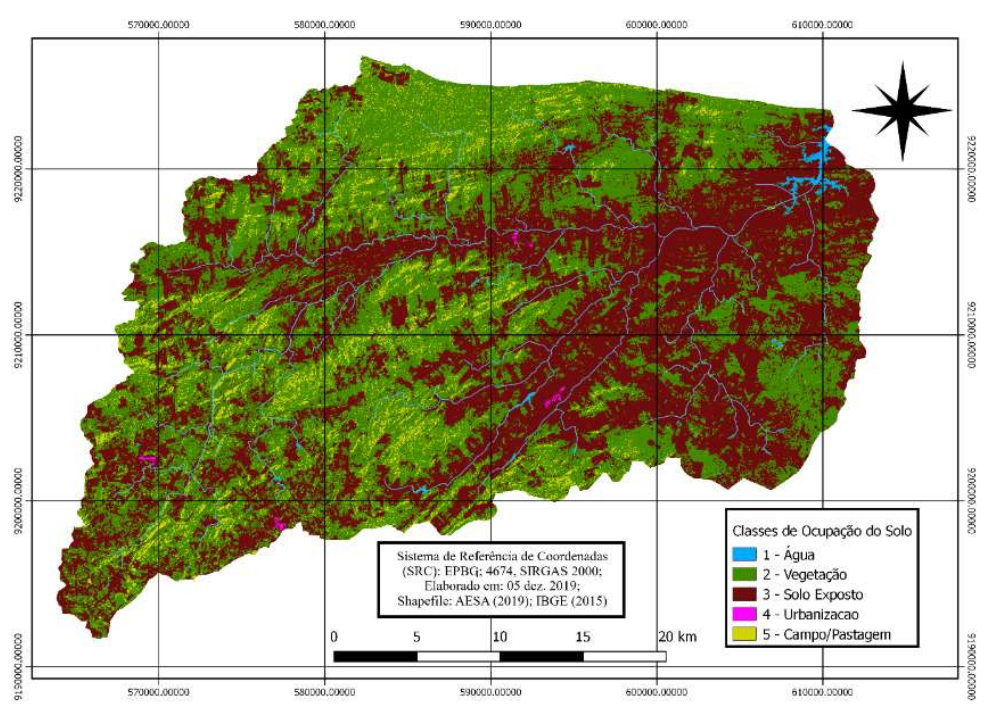

Figura 6: Mapa de uso e ocupação do solo da bacia hidrográfica do Rio Aguiar.

Tabela 3: Distribuição das classes de uso e ocupação do solo da bacia hidrográfica do Rio Aguiar.

\begin{tabular}{lll}
\hline \multirow{2}{*}{ Classe } & Área & $\mathbf{\%}$ \\
\cline { 2 - 3 } & $\mathbf{K m}^{\mathbf{2}}$ & 1,2 \\
\hline Corpos Hídricos Superficiais & 13,16 & 62 \\
Vegetação & 679,75 & $\mathbf{2 9 , 8}$ \\
Solo Exposto & 326,72 & 0,5 \\
Urbanização & 5,48 & 6,5 \\
Campos/ Pastagens & 71,26 & $\mathbf{1 0 0}$ \\
\hline Total & $\mathbf{1 0 9 6 , 3 7}$ & \\
\hline
\end{tabular}

Nota-se na Tabela 3, que 36,8\% da área da bacia do Aguiar encontra-se antropizada (entre solo exposto, urbanização e pastagens), o que serve de alerta para a ocorrência de mudanças ambientais significativas, uma vez que, Damame et al. (2019), discorreram sobre as alterações causadas por ações antrópicas aos recursos naturais, que vêm gerando impactos ambientais negativos em regiões de alta relevância ambiental, como as bacias hidrográficas, como também, estes autores em estudo realizado em sub-bacias hidrográficas no município de Campinas - SP, Brasil, concluíram que a ocupação antrópica foi a responsável explícita pelas perturbações e mudanças ambientais ocorridas nas áreas do estudo.

Ressalva-se também, a elevada concentração de áreas de solo exposto as margens ou próximas aos cursos d’água (principalmente na porção leste da bacia, onde localizam-se as terras mais planas), assim, indicando que estes locais não estão em conformidade com a legislação vigente, visto que de acordo com a Lei n.12.651 de maio de 2012, atual Código Florestal Brasileiro, essas regiões são áreas de preservação permanente (APPs), ou melhor, são áreas de incompatibilidade legal, as quais foram ocupadas/ utilizadas de forma irregular, posto que é proibido o desmatamento da cobertura vegetal (mata ciliar) destes locais em um raio mínimo de $30 \mathrm{~m}$, a depender do comprimento do leito regular do curso d’água.

\section{CONCLUSÕES}

O ambiente SIG constatou ser eficaz na caracterização dos aspectos geomorfométricos, assim como 
na avaliação do uso e ocupação do solo da bacia hidrográfica do Rio Aguiar, permitindo realizar uma abordagem sobre os problemas ambientais locais e, identificar áreas de incompatibilidade legal conforme o Código Florestal Brasileiro vigente.

A predominância de cobertura vegetal e o formato geométrico alongado da bacia hidrográfica do Rio Aguiar indicam que esta bacia não está sujeita a enchentes em condições normais de precipitação nem tão pouco a grandes processos de erosão.

Os subsídios alcançados por este estudo colaboram para o entendimento da dinâmica ambiental local, como também, podem auxiliar na gestão dos recursos hídricos e no planejamento da bacia hidrográfica do Rio Aguiar, tendo em vista, a conservação do meio ambiente e a prática do desenvolvimento sustentável na região.

\section{REFERÊNCIAS}

AHER, P. D.; ADINARAYANA, J.; GORANTIWAR, E. S. D.. Quantification of morphometric characterization and prioritization for management planning in semi-arid tropics in India: a remote sensing and GIS approach. Journal of Hydrology, v.51, n.1, p.850-860, 2014. DOI: https://doi.org/10.1016/j.jhydrol.2014.02.028

ANA. Agência Nacional de Águas. Panorama da qualidade das águas superficiais do Brasil. Brasília: ANA, 2012.

ANDRADE, C. W. L.; MONTENEGRO, S. M. G. L.; LIMA, J. R. S.; MONTENEGRO, A. A. A.; MAGALHÃES, A. G.. Modelagem hidrológica sob mudanças na cobertura vegetal de uma bacia hidrográfica no Nordeste do Brasil. Journal of Environmental Analysis and Progress, v.2, n.3, p.239-248, 2017. DOI:

https://doi.org/10.24221/jeap.2.3.2017.1446.239-248

ARAÚJO, M. S.; MARUSCHI, V. O.. Aspectos metodológicos e operacionais em morfometria fluvial, a partir do Geoprocessamento. Caderno de Geografia, v.30, n.1, p.1935, 2020. DOI: https://doi.org/10.5752/P.23182962.2020v30nesp1p19-35

ALVES, R. E.; PAULINO, H. B.; OLIVEIRA, R. M.; SOUZA, L. F.. Transformações da paisagem da bacia hidrográfica do ribeirão da picada, jataí (GO): uma análise tempo-espacial. Acta geográfica, v.9, n.19, p.109-125, 2015. DOI: http://dx.doi.org/10.5654/acta.v9i19.2284

BANERJEE, A.; SINGH, P.; PRATAP, K.. Morphometric evaluation of Swarnrekha watershed, Madhya Pradesh, India: an integrated GIS-based approach. Applied Water Science, v.7, n.4, p.1807-1815, 2017. DOI: https://doi.org/10.1007/s13201-015-0354-3

BENATTI, D. P.; TONELLO, K. C.; FARIA, L. C.; LEITE, E. C.. Morfometria e uso e cobertura de uma microbacia no município de Sete Barras, São Paulo. Irriga, v.20, n.1, p.2132, 2015. DOI:

https://doi.org/10.15809/irriga.2015v20n1p21

BERTONI, J.; LOMBARDI NETO, F.. Conservação do solo. 9 ed. São Paulo: Ícone, 2014.
BRASIL. Lei $\mathbf{n . 1 2 . 6 5 1}$ de $\mathbf{2 5}$ de maio de 2012. Dispõe sobre a proteção da vegetação nativa, e dá outras providências. Brasília: DOU, 2012

CASTRO, P.; LOPES, J. D. S.. Recuperação e conservação de nascentes. Viçosa: CPT, 2001.

CHRISTOFOLETTI, A.. Geomorfologia. 2 ed. São Paulo: Edgard Blücher, 1980.

DAMAME, D. B.; LONGO, R. M.; OLIVEIRA, E. D.. Impactos ambientais pelo uso e ocupação do solo em sub bacias hidrográficas de Campinas, São Paulo, Brasil. Acta Brasiliensis, v.3, n.1, p.1-7, 2019. DOI: http://dx.doi.org/10.22571/10.22571/2526-4338108

EMBRAPA. Centro Nacional de Pesquisa de Solos: Sistema Brasileiro de Classificação de Solos. 3 ed. Rio de Janeiro: EMBRAPA, 2013.

FERNANDES, M. F.; QUEIROZ, P.. Vegetação e flora da Caatinga. Ciência e Cultura, v.70, n.4, p.51-56, 2018 DOI: https://doi.org/10.21800/2317-66602018000400014

FARIAS, J. F.; SILVA, E. V.; NASCIMENTO, F. R.. Caracterização de Sistemas Ambientais como Base Metodológica para o Planejamento Ambiental em Bacias Hidrográficas Semiáridas. Revista GeoAmazônia, v.3, n.06, p.14-27, 2016. DOI: https://doi.org/10.17551/23581778/geoamazonia.v3n6p14-27

GERBER, D.; PERTILLE, C. T.; VIEIRA, F. S.; CORRÊA, B. J. S.; SOUZA, C. F.. Caracterização morfométrica da Bacia Hidrográfica do Rio Itajaí-Santa Catarina. Acta Biológica Catarinense, v.5, n.01, p.72-83, 2018. DOI: http://dx.doi.org/10.21726/abc.v5i1.446

KOPPEN, W. D.. Das geographische system der klimat, Handbuch der klimatologie. Berlim: Gebruder Borntraeger, 1936.

LEAL, M. S.; TONELLO, K. C.. Análise da morfometria e do uso e cobertura da terra da microbacia do córrego Ipaneminha 
de Baixo, Sorocaba/Sp. Floresta, v.46, n.4, p.439-446, 2017 . DOI: https://doi.org/10.5380/rf.v46i4.45809

LEAL, M. S.; TONELLO, K. C.; DIAS, H. C. T.; MINGOTI, R.. Caracterização hidroambiental de nascentes. Revista Ambiente \& Água, v.12, n.1, p.146-155, 2017b. DOI: https://doi.org/10.4136/ambi-agua.1909

LEPSCH, I. F.. Formação e conservação dos solos. 2 ed. São Paulo: Oficina de textos, 2016.

LIMA, K. C.; PEREZ FILHO, A.; CUNHA, C. M. L.. Características morfológicas e morfométricas dos canais de drenagem da bacia hidrográfica do rio Bom Sucesso-Semiárido da Bahia/Brasil. Revista Brasileira de Geomorfologia, v.14, n.4, p.309-317, 2014. DOI:

http://dx.doi.org/10.20502/rbg.v14i4.362

LOPES, E. R. N.; SOUZA, J. C.; SOUSA, J. A. P.; ALBUQUERQUE FILHO, J. L.; LOURENÇO, R. W.. Modelagem ambiental de bacias hidrográficas: caracterização morfométrica e pedológica da bacia do rio Una-Ibiúna, Brasil. Geosul, v.33, n.66, p.105-127, 2018. DOI: https://doi.org/10.5007/21775230.2018v33n66p105

LOPES, S. M. F.; CABRAL, J. B. P.; BRAGA, C. D. C.; RAMALHO, F. L.. Avaliação espaço-temporal do uso da terra nas bacias hidrográficas do ribeirão Paraíso-Go e córrego Cerrado/Cadunga-MG. Revista GeoAmbiente, v.1, n.27, p.114-133, 2016. DOI: https://doi.org/10.5216/revgeoamb.v0i27.44758

MACHADO, L. C.; SELVA, V. S. F.; SANTOS, S. M.. Proposta metodológica interdisciplinar como ferramenta para o potencial de conservação de nascentes. Journal of Environmental Analysis and Progress, v.3, n.1, p.008-023, 2018. DOI:

https://doi.org/10.24221/jeap.3.1.2018.1660.008-023

MESHRAM, S. G.; SHARMA, S. K.. Prioritization of watershed through morphometric parameters: a PCA-based approach. Applied Water Science, v.7, n.3, p.1505-1519, 2017. DOI: https://doi.org/10.1007/s13201-015-0332-9

RAHMATI, O.; SAMADI, M.; SHAHABI, H.; AZAREH, A.; RAFIEISARDOOI, E.; ALILOU, H.; MELESSE, A. M.; PRADHAN, B.; CHAPI, K.; SHIRZADI, A.. SWPT: An Automated Tool Based on GIS to Prioritize Sub-Basins Based on Morphometric and Top-Hydrological Factors. Geoscience Frontiers, v.10, n.6, p.2167-2175, 2019. DOI: https://doi.org/10.1016/j.gsf.2019.03.009
PHILIPPI JÚNIOR, A.; SOBRAL, M. D. C.. Gestão de bacias hidrográficas e sustentabilidade. São Paulo: Manole, 2019.

SANTOS JÚNIOR, N. R. F.; VENDRUSCOLO, J.; CAVALHEIRO, W. C. S.; SOARES, G. S.; BENTO, A. R.; ROSA, D. M.. Caracterizacion morfometrica de la subcuenca del rio Mutum-Parana, Amazonia Occidental, Brasil. Revista Geográfica Venezolana, v.1 n.SI, p.16-28, 2019

SANTOS, E. J.; FERREIRA, C. A.; SILVA JÚNIOR, J. M. F.. Geologia e recursos minerais do estado da Paraíba. Recife: CPRM, 142p.; 2002.

SANTOS, M. C.. Solos do Semiárido do Brasil: Semiárido Riquezas e Oportunidades. 10 ed. Recife: EDUFRPE, 2017.

SCHUMM, S. A.. Sinuosity of alluvial rivers on the great plains. Geological Society of America, Bulletin, n.74, p.10891100, 1963

SOUZA, J. O. P. D.; BARROS, A. C. M. D.; CORREA, A. C. D. B. Estilos fluviais num ambiente semiárido: bacia do Riacho do Saco, Pernambuco. Finisterra-Revista Portuguesa de Geografia, v.22, n.102, p.3-23, 2016. DOI: http://dx.doi.org/10.18055/Finis3737

SOUSA, W. S.; SOUSA, F. A. S.. Rede neural artificial aplicada à previsão de vazão da Bacia Hidrográfica do Rio Piancó Revista Brasileira de Engenharia Agrícola e Ambiental, v.14, n.2, p.173-180, 2010. DOI: https://doi.org/10.1590/S141543662010000200008

STRAHLER, A. N.. Quantitative analysis of watershed geomorphology. Eos, Transactions: American Geophysical Union, v.38, n.6, p.913-920, 1957. DOI: https://doi.org/10.1029/TR038i006p00913

TUCCI, C. E. M.. Hidrologia: ciência e aplicação. 3 ed. Porto Alegre: ABRH, 2004.

VASCONCELOS, J. O.; SOUZA, J. O. P.. Classificação de Unidades de Paisagem em Bacia Hidrográfica SemiáridaUma Abordagem do Índice Topográfica de Umidade. Revista Contexto Geográfico, v.3, n.6, p.66-76, 2019. DOI: http://dx.doi.org/10.28998/contegeo.v3i6.6969

VILELLA, S. M.; MATTOS, A.. Hidrologia aplicada. São Paulo: McGraw-Hill do Brasil, 1975.

ZUFFO, A.; ZUFFO, M.. Gerenciamento de recursos hídricos conceituação e contextualização. Rio de Janeiro: Elsevier Brasil, 2017.

A CBPC - Companhia Brasileira de Produção Científica (CNPJ: 11.221.422/0001-03) detém os direitos materiais desta publicação. Os direitos referem-se à publicação do trabalho em qualquer parte do mundo, incluindo os direitos às renovações, expansões e disseminações da contribuição, bem como outros direitos subsidiários. Todos os trabalhos publicados eletronicamente poderão posteriormente ser publicados em coletâneas impressas sob coordenação da Sustenere Publishing, da Companhia Brasileira de Produção Científica e seus parceiros autorizados. Os (as) autores (as) preservam os direitos autorais, mas não têm permissão para a publicação da contribuição em outro meio, impresso ou digital, em português ou em tradução. 